\title{
FLC-DTC Method for Torque Ripples Minimization of 8/6 Switched Reluctance Motors Drive
}

\author{
Hafeezul Haq \\ Department of Electrical \& Electronics Engineering \\ Karadeniz Technical University \\ Trabzon, Turkey \\ hafeezulhaq88@yahoo.com
}

\author{
Halil Ibrahim Okumus \\ Department of Electrical \& Electronics Engineering \\ Karadeniz Technical University \\ Trabzon, Turkey \\ okumus@ktu.edu.tr
}

\begin{abstract}
The switched reluctance motor gains a significant response in industries in the past decade because of its ruggedness, high torque to inertia ratio, simple structure, high reliability and inexpensive manufacturing capability. These features make it a suitable candidate for various applications and electric drives. However, In the field of electric drives a switched reluctance motor drive is having doubly salient structure thus it inherently produces high torque ripples and acoustic noise problems and its controlling difficulties that is an undesirable effect for vehicle applications, especially at low speed. The main objective of this paper is to minimize the torque ripples and to control its speed. In this paper a fuzzy logic controller based direct torque control method is used for speed controlling and for controlling of torque ripples of the $8 / 6 \mathrm{SRM}$ drive. It's modelling and application of fuzzy logic controller based direct torque control method is done in MATLAB/SIMULINK environment.
\end{abstract}

Index Terms $-S$ witched reluctance motor, Fuzzy logic controller, Direct torque control, Ripple control, Acoustic noise, Torque ripples.

\section{INTRODUCTION}

The switched reluctance motor is using from the early 19th century. The name switched reluctance comes from two characteristics of the machine "switched" and "reluctance". The Switched word comes because the machine is operating in a continuous switching mode and the stator and rotor both consist of variable reluctance magnetic circuits so the reluctance word comes from there. It has many advantages like it is inexpensive to manufacture, its simple structure, and its ruggedness[7][8]. However, it also have some disadvantages like high torque ripples, acoustic noises and controlling difficulties which prevent it from being accepted by the some industries applications [1]

Its construction is simple but its controlling is very difficult task because the phase energizing should be done at right time and angle in order to have less torque ripple and less speed oscillation. Another big problem is the double saliency construction of both stator and rotor[4], so that torque production by separate phase became a cause of high torque ripples. It also results the production of ripples in current in DC supply and demand a large filter capacitor. In other side torque ripples also produces acoustic noise, due to the induction of radial magnetic forces.
Fortunately, the power electronics and converter topologies recently have a good advancement and it became possible to control these type of machines and problems. These motor become competitive with the other AC motors in the vast industrial applications.

\section{PRINCIPLE OF OPERATION}

A magnetic reluctance gives rise in order to form stable equilibrium position in an electromagnetic system is the main principle of operation of switched reluctance machine. For production of torque the two opposite poles are excited so it attracts the nearest rotor poles and the torque is produced. After the alignment of these rotor poles with the stator poles the stator energized pole become de-energized and its adjacent stator pole become energized and it attract the other pair of rotor poles. On this way the torque is produced in switched reluctance motor and it starts running. When both the stator and rotor poles gets parallel to each other, means aligned then that position is called aligned position. During this position the phase inductance is on its maximum value and the reluctance reaches to its minimum value. When the rotor pole moves away from its aligned position the phase inductance decreases gradually. When the rotor and stator pole is in unaligned position then the phase inductance reaches to its minimum value and the reluctance goes to its maximum value.

\section{MATHEMATICAL MODELING OF SWITCHED RELUCTANCE MOTOR}

For an accurate analysis of the motor behavior, it is needed a relatively more complex mathematical approach. The instantaneous voltage across the SR motor depends on resistance of the winding and its flux linked by the winding. The flux linkages is consist of two variables, the current, ' $i$ ' and the rotor position i.e. angle ' $\theta$ '. The mathematical model describing the equivalent circuit for one phase is shown below in Fig 1. 


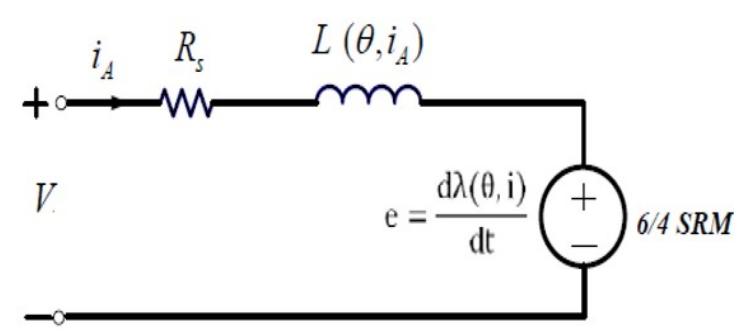

Fig 1. Equivalent circuit of one phase of Switched Reluctance Motor

$$
V=R_{s} i+\frac{d \lambda(\theta, i)}{d t}
$$

Where ' $\mathrm{V}$ ' is the applied phase voltage, ' $\mathrm{R}$ ' is the phase resistance, and ' $\lambda$ ' is flux. The flux is the product of inductance and winding current [5] as shown in Eq. 1.

$$
\lambda(\theta, i)=i L(\theta, i)
$$

2)

Substituting this in Eq. 1.

$V=R_{g} i+\frac{d L(\theta, i) i}{d t}=R_{g} i+L(\theta, i) \frac{d i}{d t}+i \frac{d \theta}{d t} \frac{d L(\theta, i)}{d \theta}$

3)

$V=R_{g} i+L(\theta, i) \frac{d i}{d t}+i \frac{d L(\theta, i)}{d \theta} \omega_{m}$

The Eq. 3. and Eq. 4. consists of three terms resistive voltage drop, inductive voltage drop and induced emf respectively. The Eq. 5. represents induced emf is as.

$$
e=i \frac{d L(\theta, i)}{d \theta} \omega_{m}=K_{b} \omega_{m} i
$$

5)

$$
P_{i}=V i=R_{g} i^{2}+i L(\theta, i) \frac{d i}{d t}+i^{2} \frac{d L(0, i)}{d \theta} \omega_{m}
$$

The energy stored in an inductor is represented by Eq. 7 .

$$
W=\frac{1}{2} L(\theta, i) i^{2}
$$

The power for an inductor is given as the rate of change of energy over time so the power is described by Eq. 8 .

$$
\begin{gathered}
P_{L}=\frac{d}{d t}\left[\frac{1}{2} L(\theta, i) i^{2}\right]=\frac{1}{2} i^{2} \frac{d L(\theta, i)}{d t}+L(\theta, i) i \frac{d i}{d \theta} \\
P_{L}=\frac{1}{2} i^{2} \omega \frac{d L}{d \theta}+L i \frac{d i}{d \theta}
\end{gathered}
$$

9)

According to law of conversation of energy the mechanical power can be found by subtracting the winding resistance losses, 'Ri2', and the losses due to inductance that is Eq. 9. from the instantaneous power[3]. So by subtracting these two value from Eq. 6.we get the mechanical power as:

$$
P_{m}=\frac{1}{2} \frac{d L(\theta, i)}{d \theta} \omega_{m} i^{2}
$$

)The mechanical power described by Eq. 10. is also expressed as the product of electromagnetic torque and rotor speed so we can calculate the switched reluctance motor torque by Eq. 11.

$$
T_{\theta}=\frac{P_{m}}{\omega_{m}}=\frac{1}{2} z^{2} \frac{d L(\theta, i)}{d \theta}
$$

)

The torque is directly proportional to the square of current so it means that the torque is independent of current. The torque will be unidirectional whatever current is positive or negative. But the torque is also directly proportional to $\operatorname{dL}(\theta, i) / d \theta$. So if the value of $\operatorname{dL}(\theta, i) / d \theta$ is positive the torque produced will be positive that means the motoring will be happened and the electrical power will be converted to mechanical power. If the value of $\operatorname{dL}(\theta, \mathrm{i}) / \mathrm{d} \theta$ is negative then the torque production will also be negative that means the generating action will happened and the mechanical power will be converted back to electrical power[3] [6].

\section{MINIMIZATION OF TORQUE RIPPLES}

Because of the large amount of its torque ripples the switched reluctance motor has limited applications. Due to these large amount of torque ripple it produces high noise and vibration. So for minimization of these high amount of torque ripple various techniques have been proposed for switched reluctance motor drive.

\section{A. Origin of Torque Ripples}

A large amount of torque ripples are produce in switched reluctance motor because of doubly salient structure of the motor. The discrete and nonlinear torque production mechanism in the motor is another reason for ripples in the torque. Therefore, instantaneous torque produced is the sum of individual phase torques. Dependency of torque on current magnitude and rotor position when operated with flat topped currents would also result in torque ripple. In conventional $\mathrm{AC}$ motors, the torque is produced due to interaction of two fluxes which are smoothly revolving around the reference frame and can be made constant by subsequent frame transformation. Absence of such reference frame transformation to eliminate the rotor position dependency because of doubly salient nature of the Switched reluctance motor insists on the control on an instantaneous basis for reduction of torque ripple. During steady state operation the 
torque ripple is calculated as the difference between the maximum and minimum instantaneous torque expressed as a percentage of the average torque. Mathematically, percentage torque ripple is expressed as given in Eq. 12.

$$
\text { Torque ripple }(\%)=\frac{T_{\text {inst }}(\max )-T_{\text {inst }}(\min )}{T_{\text {uvg }}} \times 100
$$

Where Tinst is the instantaneous torque and Tavg is the average torque.

\section{B. Fuzzy Logic Controller}

Fuzzy logic controller uses fuzzy logics which based on fuzzy set theory. These fuzzy set theory and controller represent the experience and knowledge of a human being in terms of some linguistic variables. These variables are called fuzzy rules. The Fuzzy logic controller perform the same work and operation as a human operator do by adjusting the input signal looking only at the system output. A fuzzy logic controller consist of three main sections, fuzzifier, rule base and defuzzifier[2]. Here we have two inputs Error (e) and change in error (de) and one output. We have the same seven membership functions for each of input and output. Here the 49 rule fuzzy logic controller is used. These rules are given in Table 1.

TABLE I. FuZZy RuLE’S TABLE.

\begin{tabular}{|c|c|c|c|c|c|c|c|c|}
\hline \multicolumn{2}{|c|}{$\Delta \mathbf{u}$} & \multicolumn{7}{|c|}{$\Delta \mathbf{e}$} \\
\cline { 3 - 9 } & NB & NM & NS & Z & PS & PM & PB \\
\hline \multirow{4}{*}{ e } & NB & NB & NB & NB & NB & NM & NS & Z \\
\cline { 2 - 9 } & NM & NB & NB & NB & NM & NS & Z & PS \\
\cline { 2 - 9 } & NS & NB & NB & NM & NS & Z & PS & PM \\
\cline { 2 - 9 } & Z & NB & NM & NS & Z & PS & PM & PB \\
\cline { 2 - 9 } & PS & NM & NS & Z & PS & PM & PB & PB \\
\cline { 2 - 9 } & PM & NS & Z & PS & PM & PB & PB & PB \\
\cline { 2 - 9 } & PB & $Z$ & PS & PM & PB & PB & PB & PB \\
\hline
\end{tabular}

Here in this study we will use Mamdani type of fuzzy inference system. Mamdani's fuzzy inference method is the most commonly using method. It was proposed in 1975 by Ebrahim Mamdani as an attempt to control a steam engine and boiler combination by synthesizing a set of linguistic control rules obtained from experienced human operators. The fuzzy inference file will be build using the graphical user interface (GUI) tools provided by fuzzy logic box. The surface view of these rules is as follows in Fig. 2.

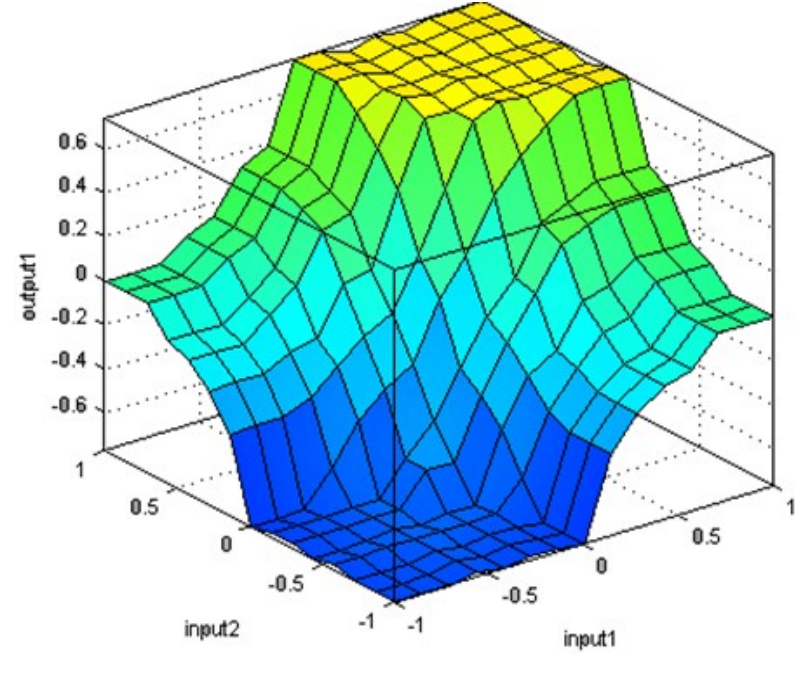

Fig 2. Surface view of rules

\section{FLC Based Direct Torque Control Method}

In advance control systems a high performance frequency control system is used which is known as Direct Torque Control System (DTC). In this method the torque of the Switched Reluctance Motor is directly controlled by controlling the magnitude of flux linkage and the change in speed of the stator flux vector. The block diagram of the direct torque control is shown in Fig. 3. The direct torque control technique is consist of three important function, hysteresis control of torque and flux, an optimal switching vector look- up table and a motor model. In Direct Torque Control method, the actual or estimated speed is compared with the reference speed, the output of the comparison is known as error signal. This error signal is applied to controller which is a Fuzzy Logic Controller. The output of Fuzzy Logic Controller gives the reference value of electromagnetic torque which is known as torque reference Tref. The reference value of torque and flux is compared with the actual value and the control signal is produce by using a torque and flux hysteresis control method. The output of hysteresis controller gives an input signal for the vector look-up table. For all possible stator flux linkage space vector positions that provides the optimum selection of the switching vector look-up table. The angle of the calculated flux which determines the region where the flux vector is excited and then the output signal is also passes through the switching table.

The pulses for invertor circuit is provided by the signals of switching table. So it is concluded that the space vector invertor is mostly depends upon three factors,

- Flux hysteresis control signal

- The angle of flux vector and the direction of the flux vector rotation

- Torque hysteresis control signal 
JAREE-Journal on Advance Research in Electrical Engineering

Volume4, Number 1, April 2020

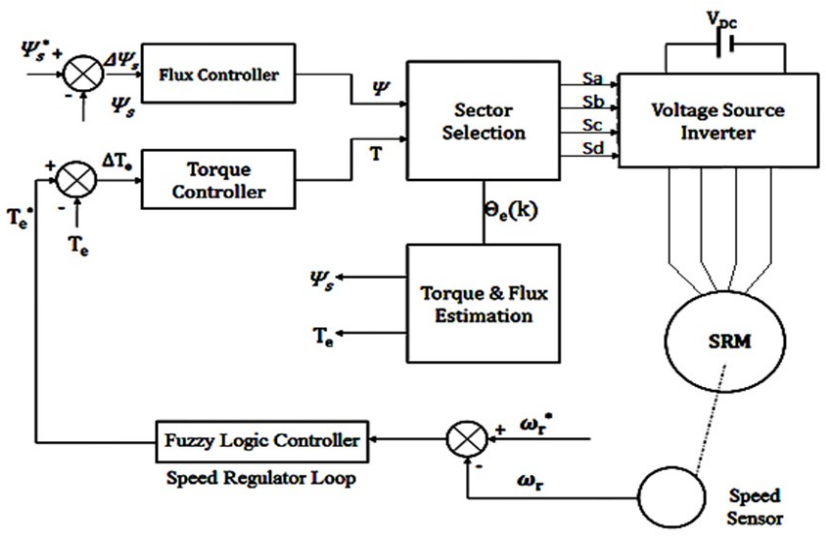

Fig 3. Block diagram of direct torque and flux control

Now Switched Reluctance Motor is simulated in Simulink environment with Fuzzy Logic Controller and result is observed for its torque ripples minimization and its speed control.

In this study the single phase $120 \mathrm{v}$ is used for the circuit. This $120 \mathrm{v}$ is converted to four phase eight pole by a converter according to pulses generated by fuzzy direct torque control circuit. This 4 phase 8 pole voltage is applied to Switched Reluctance Motor and also it is applied to speed and flux estimation block. The speed and flux is estimated from the voltage and applied to controller block as a reference.

The estimated flux and speed is applied to fuzzy based direct torque control circuit, where the gate pulses are generated for converter. The complete circuit is shown in Fig. 4.

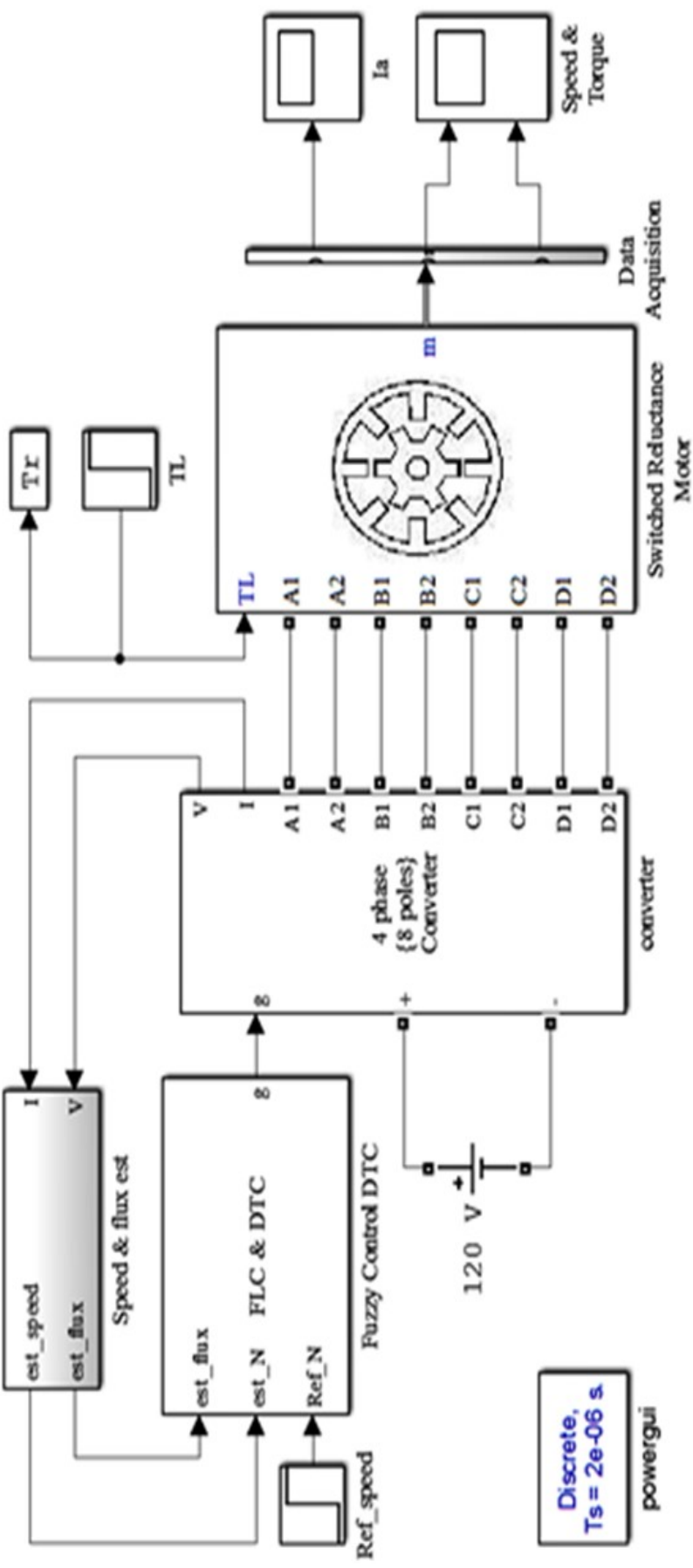

Fig 4. FLC-DTC block diagram

\section{SiMUlation AND RESUlt ANALYSIS}

First the Switched Reluctance drive is simulated for $2 \mathrm{sec}$ and for a reference input of $750 \mathrm{rpm}$ and the load torque is applied zero at starting and after $1 \mathrm{sec}$ the load torque is increased to $3 \mathrm{Nm}$. The simulation result is shown in Fig. 5. below. 
JAREE-Journal on Advance Research in Electrical Engineering Volume4, Number 1, April 2020
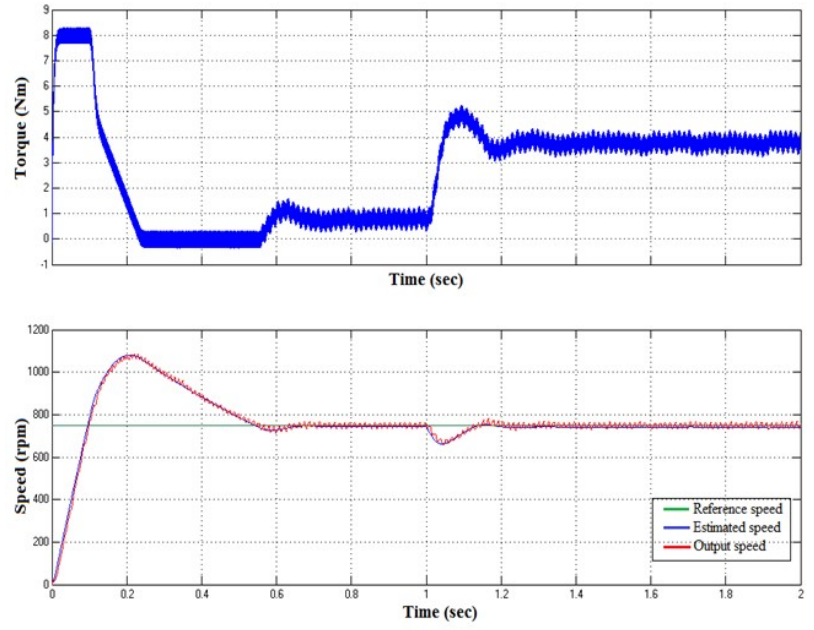

Fig 5. Simulation result for a constant Reference speed

The torque ripples are minimized to a very low value. The estimated speed is exactly as the reference speed applied and the output speed is following the estimated speed very closely. And in starting it take only $0.4 \mathrm{sec}$ to reach the exact reference speed, it is a good value. After $0.4 \mathrm{sec}$ it remains constant as the reference applied. At $1 \mathrm{sec}$ the torque is changed from zero to $3 \mathrm{Nm}$ so it effects the speed a little, after that the speed again take the reference value.

Now the switched reluctance drive is simulated for $5 \mathrm{sec}$ and the reference applied is a varying speed. The input reference speed is applied as $750 \mathrm{rpm}$ up to $2 \mathrm{sec}$. After $2 \mathrm{sec}$ the reference speed is increased to $1000 \mathrm{rpm}$ up to $5 \mathrm{sec}$. The load torque is applied as zero at starting and after $4 \mathrm{sec}$ the load torque is increased to 3 as shown in Fig. 6.
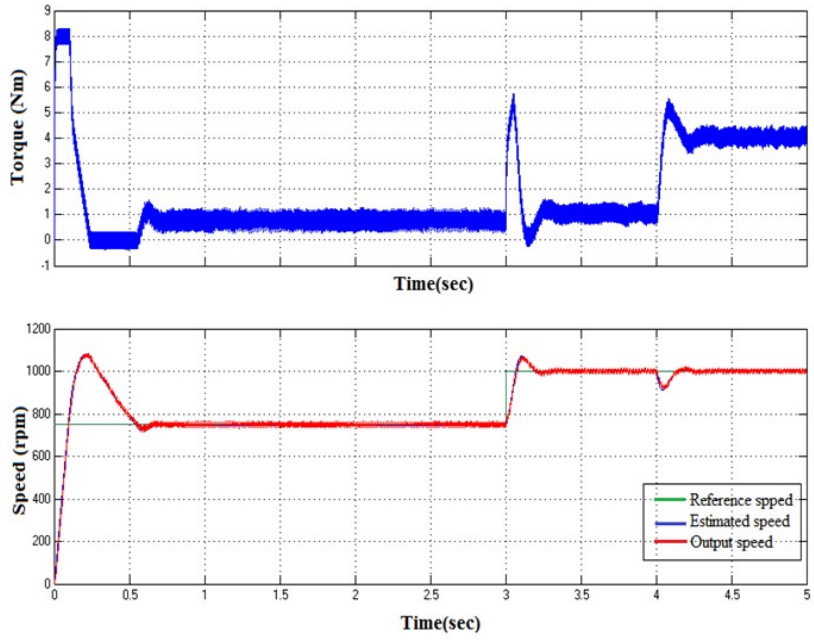

Fig 6. Torque and Speed simulation result for a varying reference

\section{CONCLUSION}

This paper focused on the minimization of the torque ripples produced by switched reluctance motor due to its doubly silent structure. It also focused on the speed control of the switched reluctance motor. From simulation it is observed that the torque is developed when the inductance changed. The switching must be done at exact angles to reduce the torque ripples and to get these exact angles, in this paper a fuzzy logic controller is used with direct torque control method to control the ripples in torque and also to control the speed of the motor. The Direct torque control method with fuzzy logic controller control the speed of the switched reluctance motor according to the required reference applied. It also reduces the torque ripples to a very low value.

\section{REFERENCES}

[1] E. S. Jebarani and K. S. Suresh, "Torque ripple minimization of switched reluctance drives - a survey," presented at the 5th IET International Conference on Power Electronics, Machines and Drives (PEMD 2010), 2010.

[2] I. H. Altas and A. M. Sharaf, "A generalized direct approach for designing fuzzy logic controllers in Matlab/Simulink GUI environment," International Journal of Information Technology and Intelligent Computing, vol. 1, pp. 1-27, 2007.

[3] V. Pushparajesh and T. Manigandan, "Torque ripple minimization of direct torque controlled four phase switched reluctance motor using artificial intelligent controller," World Journal of Modelling and Simulation, vol. 12, pp. 163-174, 2016.

[4] R. T. Naayagi and V. Kamaraj, "Optimum Pole Arcs for Switched Reluctance Machine with Reduced Ripple," presented at the International Conference on Power Electronics and Drives Systems, 2005.

[5] I.-S. Marija, T. J. Miller, S. R. MacMinn, and J. S. Thorp, "Instantaneous torque control of electric motor drives," IEEE Transactions on Power Electronics, Vol. PE-2 , Issue: 1, pp. 55-61, 1987.

[6] S. Pratapgiri and P. P. V. Narsimha, "Direct torque control of 4 phase $8 / 6$ switched reluctance motor drive for constant torque load," World J. Model. Simul, vol. 8, pp. 185-195, 2012.

[7] M. Rajib, I. Husain, Y. Sozer, M. S. Islam, and T. Sebastian, "Torqueripple minimization of switched reluctance machines through current profiling," IEEE Transactions on Industry Applications, vol. 49, pp. 1258-1267, 2013.

[8] S. Sanjib, K, S. K. Panda, and J.-X. Xu, "Indirect torque control of switched reluctance motors using iterative learning control," IEEE Transactions on Power Electronics, vol. 20, pp. 200-208, 2005. 